\title{
Developing and refining a participatory educative model with Health Science students - A case study of practice
}

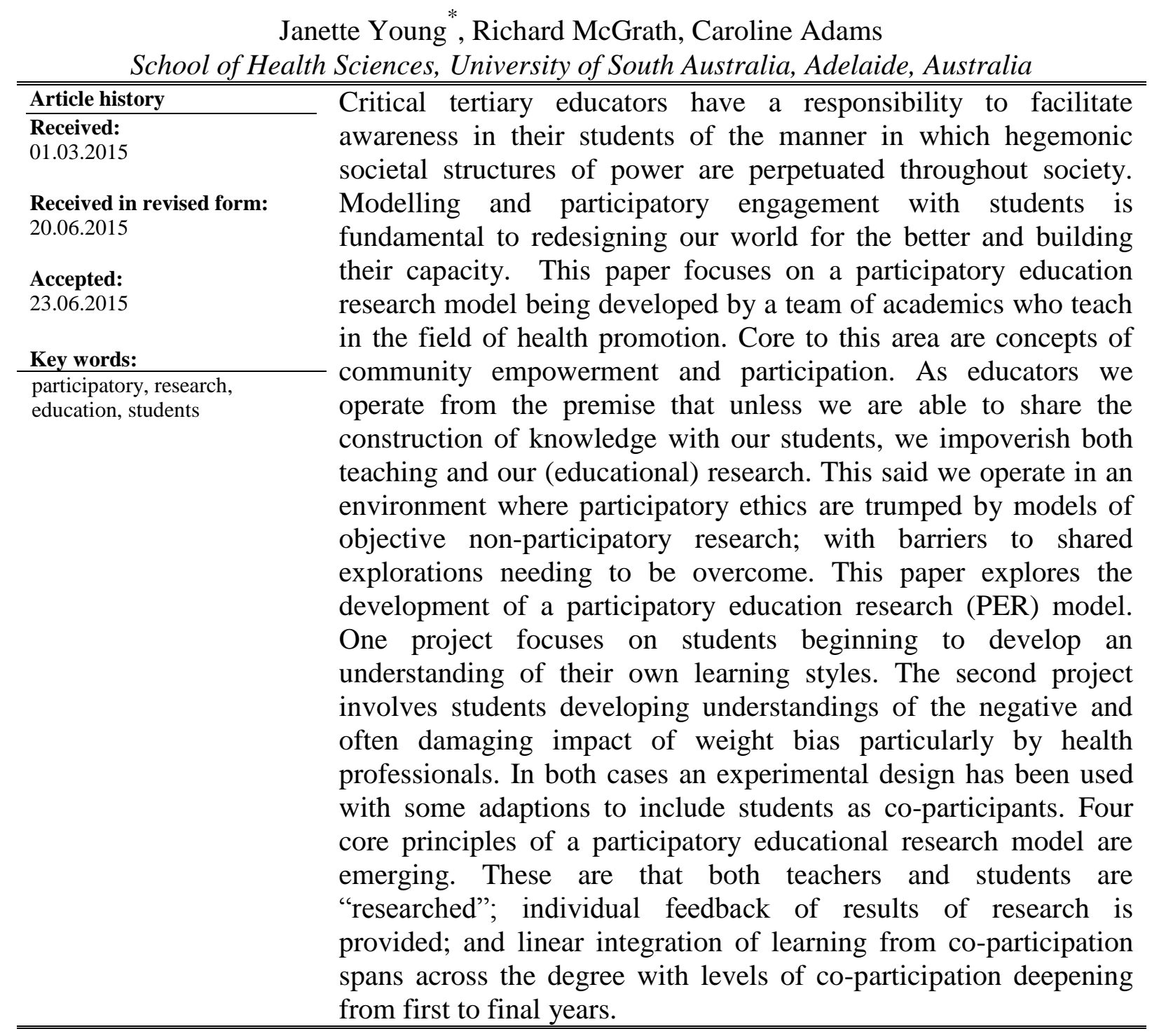

\section{Introduction}

The focus of this paper is on a participatory education research model being developed by a team of academics who teach in the areas of health policy, politics and health promotion within an undergraduate health sciences program in Australia. Core to this field of health promotion are concepts of community empowerment, participation and education. These

\footnotetext{
* Correspondence: School of Health Sciences, University of South Australia, GPO Box 2471, Adelaide SA, 5001; janette.young@unisa.edu.au
} 
principles are the same as those central to participatory education as a model and we perceive them as weaving together in the approach to educational research that we have been undertaking. We operate from the premise that unless as teaching academics we are able to share the construction of knowledge with our students in building their capacity, we impoverish both teaching and educational research. Modelling is one of the most powerful forms of learning (Bandura, 1977) and the need to instill awareness and true learning of participatory concepts led us to build real experiential examples of this into our teaching and research frameworks.

For readers who may be more familiar with contemporary education as compared to health understandings of participation and empowerment, we begin this paper with a brief outline of the health frameworks that shape our approach, linking these to participatory education literature. The Ottawa Charter (WHO, 1986) which is core to contemporary understandings of health promotion includes two action foci that have been instrumental in the development of our educational research practice. These action areas are strengthening community action, and developing personal skills.

Strengthening community action according to the Ottawa Charter involves empowerment of communities through including and engaging people in matters pertaining to their own "endeavours and destinies" (WHO, 1986). Endeavours and destinies being core to the pursuit of educational attainment as students by and large seek to achieve in order to better themselves in numerous ways. Labonte (1994) discusses the complicated dance that health workers interested in community empowerment need to recognise and negotiate, between the realities of "power over" and the enacting of "power with". Akin to teachers over students, community workers of various ilks have more power than the people whose lives they are charged with improving. Implicit in this inequity is "power over". That is the tendency and opportunity to see betterment as viewed from the perspective of those with power; rather than from that of the less powerful community. In health this often means imposing bio-medical, individualised perspectives on health issues, accompanied by deafness to the perspectives of those who suffer (ill)health indignities or impairments. In contemporary Australia one of the most starkly differentiated differences regarding ill health origins is that of western ahistorical bio-medical understandings of Indigenous health compared to that of Indigenous communities" own views. The history of colonisation and subsequent disempowerment is central to their understanding of the health inequities they experience (Sherwood \& Edwards, 2006).

Developing personal skills is the second action area from the Ottawa Charter that neatly dovetails with participatory education understandings and is implicit in the participatory educational research cases to be discussed. We are seeking to develop the personal skills and capacities of our students as critical thinkers and learners; and as non-clinical health professionals able to operate from understandings of "power with" to enable and foster empowerment and strengthen community action.

Both participatory education and community empowerment understandings outlined above have theoretical and philosophical connections to the work of Paulo Friere (1970). Friere's perspective, based in educational work in developing countries, was that education should enable both individual and collective transformations particularly with regard to oppressive practices and circumstances that individuals and communities may be subject to. Nel and Romm (2014) pick up on the threads of Friere-ian thought when they note that "(p)articipatory educational research is committed to developing knowledge through mutual 
co-construction" (2014:I). They note "an action agenda" (Nel \& Romm, 2014:I) focused on changing participants including the researchers/teachers themselves. Hence teachers and students are not two discrete categories of people but rather are construed as co-participants in researching and developing deeper understandings (McGrath 2010). Teachers have a duty to generate knowledge, but this is not to be knowledge in isolation from their relationship and relations with their students. As Ryan and Viete (2009:305) argue, educators and students can "learn from each other through the collision, discussion, and reflection of our myriad experiences".

Romm (2014) elaborates on the model of research she coins "active research". This model differs from archetypes of action research that involve cycles of inquiry that may in fact not match with the needs and availabilities of co-participants. The commitment is to shared and engaged processes of deeper understandings rather than to a recipe of research process.

\section{Context}

The research outlined is conducted mainly with students from a first year undergraduate degree in health science. The degree offers a broad non-clinical program that has multiple pathways that graduates can pursue including research, health promotion, further studies in allied health, marketing and sales, and health administration. The program is a three year undergraduate which has few unique (i.e. their student cohort only) courses. Students begin with a core course focused on critical thinking skills as applied to understanding health systems. This is followed by a second course (first year, second semester) where our students are joined by food sciences and nutrition students - Health Promotion. It is in these two courses that the research projects have been undertaken. The positioning of these two courses in first year means that we are able to work with them exploring the nature of power from the start of their program. The student cohort consists mainly of school leavers with a few slightly older participants; and tends to be skewed towards females (roughly 70\%). Most have had little exposure to learning outside of the structured school classroom environment.

The staff involved with the students in the research included three full time staff and several sessional tutors. Teaching staff come from diverse backgrounds including social work, recreation management, sociology, nursing, human movement, history, and health promotion. They have ranged from extremely experienced tutors to a new graduate.

In exploring the use of more participatory and empowering approaches in our teaching research two distinct projects have been undertaken. One project focuses on students beginning to develop an understanding of their own learning styles. The second involves students developing understandings of the negative and often damaging impact of weight bias perpetuated by health professionals. In both cases an experimental design was used. However each study design was adapted to include students as co-participants. While as researchers we were obliged by ethics committee guidelines and non-participatory frameworks to disguise some aspects of the research projects in initial stages, we sought to include students as coparticipants via debrief sessions where students could discuss their experiences of being "experimented on"; or explore findings from the research. The next section of this paper will briefly detail each research study, its rationale and data collection methods and summative findings. The discussion section identifies some key issues that have been encountered in the application of participatory educational research; and four key principles that are emerging. 


\section{Study 1: Student Learning Styles}

The first participatory study evolved from the teaching team's interest in assisting students to gain some understanding of their own approaches to learning. A core competency embedded within many tertiary institutions, including the authors', is the requirement to facilitate the development of tertiary students into lifelong learners (Dunn, 1984). As a consequence it appears logical that becoming aware of one's own learning styles and tendencies would assist in developing as a lifelong learner (McGrath, Young \& Adams, 2015). In addition, having an awareness of student learning styles has been identified as a useful tool for educators as it can enable teachers to target approaches and develop strategies that stretch students' learning (Manolis, Burns, Assudani \& Chinta, 2013). The initial aim of the study was to provide first year students with tools for understanding their own learning styles and preferences. However, rather than merely provide students with "data" about themselves the study incorporated an opportunity for both students and teachers to consider the intersection of teacher and student learning styles. It also provided the educators with valuable information about how best to teach and shape teaching material for the cohort. Each study received approval from the university's human research ethics committee.

Following reviews of previous tertiary student learning style studies as well as drawing on our own teaching experiences with past first year cohorts, we hypothesized that first year tertiary health science students would have clear groupings of learning styles, however they would also be heterogeneous. That is there would be a variety of learning styles identified across the student cohort. Previous studies of clinically focused tertiary students (for example physiotherapy, nursing, pharmacy) found some diversity of learning styles however there tended to be homogeneity within specific professions. Zoghi et al. (2010) identified physiotherapy, paramedic and pharmacy students' learning styles were very similar in regard students' preference towards practical application of ideas that focused on specific problems and solutions. Conversely D'Amore and colleagues (2012) found the learning styles of nursing students tended towards viewing situations from a variety of perspectives and adopted more inductive reasoning techniques.

The study was created and implemented within the theory advocated by Kolb (1984) who proposed an experiential learning theory that drew from others such as Dewey, Piaget and Lewin (Coffield, Moseley, Hall \& Ecclestone, 2004). For Kolb (1984: 41) "learning is the process whereby knowledge is created through the transformation of experience. Knowledge results from the combination of grasping experience and transforming it”.

This study incorporated using both the Kolb Learning Style Inventory (KLSI) (Kolb 1984) and the Visual, Auditory, Kinaesthetic (VAK) (Dunn 1984) measures. The use of both the KLSI \& VAK measures was in response to academic criticisms that the use of a singular tool to understand student learning styles was not suitable (Manolis et al., 2013). In addition, the teaching team believed the use of two learning style measures would provide a broader understanding of students' learning style preferences and assist students in developing an understanding that there are a variety of aspects related to learning. Thus each student could be seen as having a unique style of learning incorporating different factors.

The KLSI and VAK were developed into an online, self-completed survey. The survey was not assessable but students were provided with an opportunity to complete the online questionnaire during a scheduled teaching session. Students were asked to provide their student identification number in order to have their individual results returned to them. 
Demographic information such as age and gender were also collected. The survey took approximately 15 minutes to complete. The students were briefed prior to completing the online survey in regard to the purpose of the study in the tutorial session. Individual and collated student KLSI and VAK results were provided in hard copy two weeks later during a scheduled lecture at which the collated results were discussed with students. The teaching/research staff involved in the course completed a hard copy version of the survey during non-class time prior to the student data collection sessions. The teaching staffs results were also provided to students and comparisons were made between staff and student results.

Results from the study indicated that no single learning style preference dominated across the student cohort. It also identified the teaching staff as being co-located across a number of learning styles in line with the student cohort. A discussion board was set up on the course home page for students to post any comments, questions or thoughts they might have had regarding the process, findings, their own profiles etc. However there were no postings on this board and despite encouragements to talk to staff or discuss amongst themselves it appeared very little occurred. In theory adopting a partnership learning model provided an opportunity for staff and students to develop rapport and empathy in relation to learning styles. In reality minimal student-teacher or even student-student interaction seemed to happen at this time. However, we have received some positive reflective feedback from students in subsequent years as they have progressed through their degree.

\section{Study 2: Weight Bias Study}

The second participatory study originated in the teaching team's awareness of research indicating that negative attitudes (especially from health professionals) towards obese people may have significant negative impacts on overweight individual's health (Major, Hunger, Bunyan \& Miller, 2014; Puhl \& Brownell, 2010). In addition weight as a direct determinant of health is being challenged by research (Bacon, 2010; Gaesser, 2013; Gagnon-Girouard et al., 2010). Hence our concern was that significant mental health damage might be unwittingly imposed by prejudice from health professionals (including health promoters) ironically in regard to a perspective that is being reviewed and revised as to its health implications.

The aim of the study was to assist our first year Health Science students in developing an ethical understanding of the potentially negative influences that they may have in relation to the issue of weight bias. In addition as teaching staff we were keen to explore how student perceptions could be altered mitigating potential weight bias in future student cohorts. The core of this study involved the use of a blind pre/post-test experimental method that sought to understand whether providing students with a learning opportunity focused on the "causes" of obesity influenced their levels of weight bias. Therefore staff did not undertake the test unlike the learning styles study.

As the focus of this study was to explore students' perceptions concerning weight the implementation of the study was initially conducted in a more covert manner. Students were informed that the task of completing the survey was to provide an experience of being subjected to a pre/post research methodology. A covert approach was considered necessary as the evidence is that there are a number of topics, prejudices being one, where respondents may tend to seek to please the researcher even if responses are anonymous (Akrami \& Ekehammar, 2005; Glaser \& Knowles, 2008). Hence our interest in co-participation and democratizing of the research process needed to be tempered to a greater extent than in the relatively benign topic area of identification of learning styles. 
Data was again collected using an online questionnaire however to limit the acquiescence potential of students in relation to the topic the survey included a number of distractor items as well as weight bias measures. Students were informed they were to take part in a learning opportunity that involved completing an online survey that covered a number of population health research measures. It was explained that they were experiencing the feeling of doing this for themselves as in the near future they might well be administering such surveys to other people. The survey included a number of validated questionnaires covering aspects such as physical activity (Giles-Corti et al., 2006), mental health (Tennant et al., 2007), stress (Cohen, Kamarck \& Mermelstein, 1983), smoking (Vries et al. 1995) as well as key weight bias measures such as attitudes to fatness (Crandall 1994), dieting beliefs (Allison, Basile \& Yuker, 1991) and beliefs about obese people (Stotland \& Zuroff, 1990).

A key aim of this study was to explore the potential influence particular teaching materials could have in relation to influencing students' weight prejudice. The teaching team devised a research process that was interwoven into scheduled teaching tutorial sessions as well as an assignment. Three tutorial classes were randomly allocated a teaching focus concerning obesity these being diet/exercise, genetics/environment and Health at any Size (GagnonGirouard et al., 2010). The fourth tutorial class was allocated a teaching focus on smoking as a control group. The teaching focus was aligned with the requirements for the first individual assignment, a written essay due later in the semester. The pre-intervention online survey was conducted in the first week, with the subsequent post-intervention survey in week six of semester.

After completing the pre-intervention survey students were provided with five core readings that reflected the focus of their allocated tutorial, with students then being required to source two more peer reviewed journal papers. This literature was discussed in tutorials and students were required to submit an essay based on the compiled literature. Following submission of the assignment, students were required to again complete the online survey.

As with the learning styles survey, the research team sought to democratize the research process, through the use of a debrief session following the post-survey data collection. The aim of this session was to enable students to compare their learnings across class groups and allow staff to openly discuss and explore the nature and impacts of weight-prejudice with students. The debrief session also provided an opportunity for students to discuss their experiences of being "experimented on".

Data findings from the study identified that some changes concerning students' perceptions of obese people and obesity could be affected through the teaching material and foci. The debrief session conducted with students revealed their interests in their critical learnings as well as the delight of some (probably the biggest surprise to teaching staff) at being part of a covert research process.

\section{Summing up}

In summary, while the learning styles study provided an opportunity for students to be aware of the nature and focus of the research from the outset, this was not possible with the weight bias study due to the potential of students acquiescing or prejudicing survey findings. To enable students to be "involved" in each study, debrief sessions were held where students received their own results. Discussions were conducted with students during the scheduled 
teaching session to ascertain their views and perceptions concerning their findings as well as reflect on their involvement in the studies.

Some students indicated their interest in their own learning style results, however few commented on being involved in the study. In relation to the weight bias study some students reacted positively at being involved. A number indicated surprise at the covert nature of the study and were interested with being the focus of the research rather than with the outcome per se.

\section{Discussion - dilemmas and emerging principles}

Seeking to conduct participatory research studies with students has raised a number of dilemmas. Ethics committee frameworks of understanding and the multi-layered realities and theories of student "co-participation" are the most pertinent for us as a teaching team. Some principles and parameters are emerging with regard to how it is possible to democratize aspects of our educational approach and seek to redistribute the inherent power in the researcher: researched and student: teacher relationships we exist within.

\section{Ethics committee requirements}

Conducting participatory research with students studying in the domain of health sciences raised a number of dilemmas for the teaching team. The most obvious and time-consuming was ethics requirements of the institution. Even though both studies with students were posited as a learning opportunity, the ability to collect individual identifiable data was an issue for the ethics committee. The need to adhere to research anonymity and confidentiality requirements for human research was viewed by the ethics committee as paramount. The academic research team was required to identify how individual students' results could be kept from being identified by their peers numerous times throughout the ethics application process. In addition, providing individual results within a group environment (i.e. at a regularly scheduled lecture) was not supported when the ethics application was first submitted. The research team was required to restate the rationale and necessity of providing students with individual results through the use of student identification numbers to enable a collegiate debrief session to be conducted.

Research participant anonymity has been critiqued in a number of ways. This ranges from questioning for whom "anonymity" is really for (the researched, or the researcher); to observations that anonymity may not be as important to participants as it is to ethics committees (Kusenbach, 2005) and even to concerns that imposed anonymity such as the use of pseudonyms may be distressing for some research participants (Grinyer, 2009). What we were seeking in our research approach was a more sophisticated understanding of ethical engagement with our research participants than simply ethics $=$ anonymity. In line with

theorists such as Reason (2006), Reason and Bradbury (2008) as well as Khanlou and Peter (2005) and Young (2004) our research needed to encompass both an ethical approach to seeking data that could in time be published (addressing requirements imposed on us as academics) in combination with an applied ethics need to position student capacity development and participatory principles in our undertakings as well. An un-nuanced ethical approach to identification of participants was not only contrary to the teaching outcomes we were aiming for but also had potential for disempowering our students. To have not advocated to ensure that individuals could keep track of their own results was counter to the 
philosophical framework of participatory education we were seeking to undertake.

A second kind of dilemma was also posed by research requirements. Research ethics has a focus on participants having the ability to refuse or withdraw from a study at any time and hence research activity per se could not be assessable. This is a paradoxical dilemma. On one level the requirement meshes with notions of democratizing the student: teacher relationship. Students should not be held hostage to teaching researchers' agendas. Conversely, students who enter the program need to have achieved high entry scores, meaning that pragmatically we have a very results driven cohort, especially when they are largely fresh from high school. This created a tension between ethics requirements of not requiring students to undertake the questionnaire and our interest (which actually dovetails with many students' own) in promoting student learning.

While as per ethical requirements the teaching team did inform students they were not required to complete any of the online questionnaires across both studies, we also stressed the importance of students' involvement as a learning opportunity. Building the opportunity to undertake the questionnaires in class time and encouraging students that this would assist them in their own learning were two techniques undertaken to respond to the potential of having no students complete either survey. These approaches lead to over $90 \%$ of students responding in each study, a response rate that was particularly important for the overall research foci of the weight-bias study due to our interest in the possibility of shifting student opinions.

\section{Student engagement}

Another complication to the participatory research process was that the students we identified as "sharing" with - did not seem to respond to our invitation! While we received some interactive responses from our students following the weight bias study, this was not prodigious and most did not involve themselves to any great degree. It may be that this is largely a reflection of the timing of the two studies. The evidence is that transitioning to university is stressful and even overwhelming for many young people (King, Garrett, Wrench \& Lewis, 2011; Leahy et al., 2010). The learning styles study was undertaken in the first semester of first year. The distinct lack of engagement regarding the study in this semester may well be a reflection of this. The fact that we have received greater engagement with the study undertaken in the second half of first year indicates that timing may be a crucial factor in considering participatory approaches. Educators need to be aware of the broad emotional demands on their students, for example in first year, first semester transitions as these may have implications for student research co-participation.

\section{Conceptual dilemmas}

At the heart of the above participation/requirement dilemma sit three conceptual conundrums when educators wish to apply participatory approaches in their teaching. The dilemmas hub around the slippery concept of "empowerment".

Firstly, as Friere (1970) identified, those who are powerless can be intensely embedded in their powerlessness. "Learned helplessness" is the psychological framework that Seligman (1972) identified whereby when people are unable to escape negative experiences they become passive in the face of even extreme abuses. While the educational experience may not have been overtly oppressive to many of our students, they have learned to operate within (successfully given the high marks required to enter our program) non-participative 
educational frameworks. Essentially students have learnt to become passive recipients of knowledge. This is especially so for those students straight from high school, who have been drilled into giving concrete answers in order to do well in exams. Most students are also undertaking courses that demand rote learning. It could be argued that some unlearning in how to learn needs to occur in new students. When confronted by the opportunity to be coparticipants in a learning environment students appear to revert to the safety of nonengagement for fear of giving "wrong" answers. Students may be acquiescing to a form of learning practice they are more comfortable with and which (from their perspective) does not endanger their grades. This is very much evidenced by a common question frequently asked by students "will I lose marks if I say/do ...?".

A second dilemma is that of inherent inequality. Returning to the concepts of "power over" and "power with" (Labonte, 1994) there is an inherent inequity within the teacher: student relationship. Indeed, the very choice of wanting to empower students as outlined in this paper is based on the "power over" that teaching staff hold. Educators are able to make choices that have the ability to impact on students. It is a power that we are seeking to share, however it is tempered by levels of knowledge with regard to learning and education that staff have (and should have) in comparison to students. While each student brings their own unique experiences and learnings, educators should have understandings at a higher level than that of their students (Brufee, 1999). Core to the role of educator is the task of communicating higher levels of knowledge to students. The teaching team have all worked within the field that we now teach in for longer than most of our students have been alive! We have considerable knowledge bases and a large scaffold of understandings in comparison to our students. As such we are expected by our employer and students to lead in the educational process.

The requirement for educators to have greater knowledge than students, and for educators to hold some power over students does not stand alone. Educators have levels of responsibility for the learnings of students. Within higher education external regulators including boards of practice and registration in the health industry as well as tertiary sector quality frameworks influence content and approaches in education. Indeed as a teaching team we have been able to undertake the participatory research projects outlined here because the program is not discipline specific. However, the teaching team is still held responsible from both structural and moral points of view for a proportion of student outcomes.

It is notable however, that in a manner that is hidden and generally unknown to students they do have some "power over" teaching staff. Staffs' ability to seek and secure tenure and/or promotions includes requirements to present positive student course satisfaction responses as proof of quality teaching. When taking students' out of their comfort zone (aka learned helplessness) there is the risk of poor student evaluations that can affect staff morale and career pathways. This conundrum of unknowing power over, in combination with a degree of learned helplessness on the part of students has the potential to create resistance to approaches of power sharing between students and teachers.

\section{Emerging principles}

Four integrated principles have been emerging as we have developed a model of participatory educational research.

Firstly we seek to diffuse the researcher: researched distance through ensuring that it is not only students who are "researched". In keeping with this principle we are considering whether it may be appropriate for staff to also undertake the weight bias questionnaires. Being seen to 
undertake them in theory gives us more equity with the students; although it might also lead to students feeling stressed by a need to give "right" i.e. aligned to teachers' answers. We may indeed be hiding our own fears of being shown as prejudiced by not standing on equal ground with students and having our own bias' part of a collective public presentation. We are yet to make a decision as to how this will be implemented when we seek to repeat the study in the near future.

A second principle is that of seeking to ensure that feedback is of personal and/or professional benefit to each co-participants. Providing students with individual results concerning their learning styles is viewed as an opportunity for students to develop self-reflective capacities. The opportunity to reflect on their own results within each of the studies can assist students with a deeper understanding of what it can be like for others in the community to be involved in research; and we aim by modelling an empowering approach to provide students with an experiential learning opportunity that will influence their future professional practices. There is scope for teaching staff to reflect more on their own learning approaches and perceptions of weight. This is one of the aspects of the model that has been focused on least to date but it bears more investigation as part of systemically enhancing teaching and hence learning and capacity development for students.

The third principle of the approach we are developing is that of linear integration of learning across year levels. Learning is developmental, building from one level of complexity to another (Bruner, 1975; Puntambekar \& Hubscher, 2005). The first year experiences of the two studies outlined are beginning to be actively incorporated into later courses by the academic teaching team. Students are reminded of their involvement in the studies in second and third (their final) years. Some students recall the learning styles activity but others do not, however returning to their results (which are accessible from teaching staff because of the collection of student identification numbers) gives an opportunity for reflective learning. This is a factor that we are planning to embed within assessment items in these consequent years; currently it is informal. In addition both of these second and third year courses are applied and students work with external community based stakeholders. This is a key opportunity to link their own experiences of being "researched" and of power sharing to various projects involving community development and engagement.

The fourth principle of the approach we are developing is that of levels of co-participation. Given the passage of time it is now possible to be integrating some of the students who undertook the learning styles and weight-biases studies into the staff-participants research team. Previous first years are now providing advice as to how to refine the pragmatics of the studies, assisting in pursuing ethics approval and even helping to produce journal papers (this being one such example). Participatory educational engagement needs to be balanced against the needs, interest and capacity of students; but progress can be rapid as seen in the first to second semester implementation of the two studies. By third year individual students can have capacity to be co-participating at a higher level than is possible in first year. These participatory skills are part of community and related fields that graduates of the program may be employed within following completion of their degree.

\section{Conclusion}

The focus of this paper has been to explore the development of a framework through which a team of teaching academics incorporate participatory educational research into the curriculum. Nel and Romm (2014:I) point out that "[t]eachers should be forming and re- 
forming frameworks to understand practice and should take into account that teaching is about constructing the curriculum with learners, using their experiences, cultural and linguistic resources and interpretive frameworks". As teaching staff we are in the process of re-democratizing aspects of the power-inequity that exists between ourselves and students. Humans are constrained by, but also construct their own social environments as knowledgeable agents in their own worlds (Giddens, 1984). It is possible to actively reconstruct social relations so that power is shared more equitably. While in the first instance students may be overwhelmed and perhaps too embedded in alternate understandings of educational power to do anything other than bow to the requests for "obedience" we as teaching staff may seem to be proffering; the repetition of our actions as teachers has the potential to begin to shift the framework that we collectively are embedded in leading to some repositioning of the "power over" to "power with". Rather than simply rendering students as passive recipients and denying them opportunity to share their knowledge (Taines, 2010) we seek to shift the power dynamic that exist between teachers and students/youth. As students become more comfortable with aspects of power we are able to share with them together we reconstruct the power differentials.

Benjamin Franklin said: "( $\mathrm{t}$ )ell me and I forget, teach me and I may remember, involve me and I learn." Participatory educational approaches and research take us all, students and teachers on a journey of empowerment and capacity development.

\section{Acknowledgements:}

Many thanks to Kim Dell (undergraduate research assistant) for her assistance in completing this manuscript

\section{References}

Akrami, N., \& Ekehammar, B. (2005). The association between implicit and explicit prejudice: The moderating role of motivation to control prejudiced reactions. Scandinavian Journal of Psychology, 46(4), 361-366.

Allison D., Basile V. \& Yuker, H. (1991). The measurement of attitudes toward and beliefs about obese persons. International Journal of Eating Disorders, 10:599-607.

Bacon, L. (2010). Health at every size: The surprising truth about your weight. Dallas: BenBella Books.

Bandura, A. (1977). Social Learning Theory. Oxford, England: Prentice-Hall.

Bruffee, K. A. (1999). Collaborative learning: Higher education, interdependence, and the authority of knowledge. Baltimore: Johns Hopkins University Press.

Bruner, J. S. (1975). From communication to language: A psychological

perspective. Cognition, 3, 255-287.

Coffield, F., Moseley, D., Hall, E. \& Ecclestone, K. (2004). Learning styles and pedagogy in post-16 learning: A systematic and critical review. London: Learning Skills Research Centre.

Cohen, S., Kamarck, T., \& Mermelstein, R. (1983). A Global Measure of Perceived Stress. Journal of Health and Social Behavior, 24: 385-396.

Crandall, C. (1994). Prejudice Against Fat People: Ideology and Self-Interest. Journal of Personality and Social Psychology, 66(5): 882-894.

D’Amore, A., James, S., \& Mitchell, E. (2012). Learning styles of first-year undergraduate nursing and midwifery students: A cross-sectional survey utilising the Kolb Learning Style Inventory. Nurse Education Today, 32, 506-515.

Dunn, R. (1984). Learning style: State of the science. Theory into Practice, 23(1), 10-19. 
Freire, P. (1970). Pedagogy of the Oppressed. New York: Seabury Press.

Gaesser, G. A. (2013). Big fat lies: The truth about your weight and your health. California: Gurze Books.

Gagnon-Girouard M-P., Gegin, C. , Provencher, V., Tremblay, A., Mongeau, L. , Boivin, S. \& Lemieux, S. (2010). Psychological Impact of a "Health-at-Every-Size" Intervention on weight-Preoccupied Overweight/Obese Women. Journal of Obesity, Article ID 928097:1-12.

Giddens, A. (1984). The Constitution of Society : Outline of the Theory of Structuration. Cambridge: Polity Press.

Giles-Corti, B., Timperio, A., Cutt, H., Pikora, T. J., Bull, F. C., Knuiman, M., Bulsara, M., Van Niel, K. \& Shilton, T. (2006). Development of a reliable measure of walking within and outside the local neighborhood: RESIDE's Neighborhood Physical Activity Questionnaire. Preventive medicine, 42(6):455-459.

Glaser, J., \& Knowles, E. D. (2008). Implicit motivation to control prejudice. Journal of Experimental Social Psychology, 44(1), 164-172.

Grinyer, A. (2009). The Anonymity of Research Participants: Assumptions, Ethics, and Practicalities. Pan, 12(1), 49-58.

Khanlou, N., \& Peter, E. (2005). Participatory action research: considerations for ethical review. Social Science \& Medicine, 60(10), 2333-2340.

King, S., Garrett, R., Wrench, A., \& Lewis, N. (2011). The loneliness of relocating: Does the transition to university pose a significant health risk for rural and isolated students? Paper presented at the First Year in Higher Education Conference, Brisbane, Australia. http://www.fyhe.com.au/past_papers/papers11/FYHE-2011/content/pdf/16B.pdf

Kolb, D. (1984). Experiential learning: experience as the source of learning and development. Englewood Cliffs: Prentice Hall.

Kusenbach, M. (2005). Across the Atlantic: current issues and debates in US ethnography. Qualitative Social Research, 6(3).

Labonte, R. (1994). Health Promotion and Empowerment: Reflections on Professional Practice. Health Education Quarterly, 21(2), 253-268.

Leahy, C. M., Peterson, R. P., Wilson, I. G., Newbury, J. W., Tonkin, A. L., \& Turnbull, D. (2010). Distress levels and self-reported treatment rates for medicine, law psychology and mechanical engineering tertiary students: Cross sectional study. Australian and New Zealand Journal of Psychiatry, 44, 608-615.

Major B, Hunger J, Bunyan D \& Miller C (2014). The ironic effects of weight stigma. Journal of Experimental Social Psychology, 51:74-80.

Manolis C., Burns D.J., Assudani, R., \& Chinta, R. (2013). Assessing experiential learning styles: a methodological reconstruction and validation of the Kolb learning style inventory. Learning and Individual Differences, 23, 44-52.

McGrath, R. (2010). A critical self-reflection of teaching "disability" to international business students, Journal of International Education in Business, Vol.3, no.1/2, pp.20-33

McGrath, R., Young J. \& Adams C. (2015). Assessing, sharing and responding to learning styles in Bachelor of Health Science students and their teachers. Focus on Health Professional Education: A Multi Disciplinary Journal. (In Review)

Nel, N. \& Romm, N. (2014). Editor's Forward. Participatory Education Research, 1(1): I-II.

Puhl, R. \& Brownell, K. (2010). Confronting and coping with weight stigma: an investigation of overweight and obese adults. Obesity, 14(10):1802-1815.

Puntambekar, S. \& Hubscher, R. (2005). Tools for scaffolding students in a complex learning environment: What have we gained and what have we missed?. Educational psychologist, 40(1), 1-12. 
Reason, P. (2006). Choice and quality in action research practice. Journal of management inquiry, 15(2): 187-203.

Reason, P. \& Bradbury, H. (2008). The SAGE handbook of action research: Participatory inquiry and practice. London: Sage.

Romm, N. (2014). Active and Accountable Social Inquiry: Implications and Examples. Participatory Education Research, 1(2):13-20.

Ryan, J. \& Viete, R. (2009). Respectful interactions: learning with international students in the English-speaking academy. Teaching in Higher Education, 14(3):303-314.

Seligman, M. E. (1972). Learned helplessness. Annual review of medicine, 23(1), 407-412.

Sherwood, J. \& Edwards, T. (2006). Decolonisation: A critical step for improving Aboriginal health. Contemporary Nurse, 22(2), 178-190.

Stotland, S. \& Zuroff, D. (1990). A new measure of weight locus of control: the Dieting Beliefs Scale. Journal of Personality Assessment, 54(1-2):191-203.

Taines, C. (2010). Educational or Social Reform? Students Inform the Debate Over Improving Urban Schools. Education and Urban Society. doi: $10.1177 / 0013124510392566$

Tennant, R., Hiller, L., Fishwick, R., Platt, S., Joseph, S., Weich, S., Parkinson, J., Secker, J. \& Stewart-Brown, S. (2007). The Warwick-Edinburgh mental well-being scale (WEMWBS): Development and UK validation. Health and Quality of life Outcomes, 5(1):63-75.

Vries, H. D., Backbier, E., Kok, G., \& Dijkstra, M. (1995). The Impact of Social Influences in the Context of Attitude, Self-Efficacy, Intention, and Previous Behavior as Predictors of Smoking Onset. Journal of Applied Social Psychology, 25(3): 237-257.

World Health Organisation (1986). The Ottawa Charter for Health Promotion. Geneva, Switzerland.

http://www.who.int/healthpromotion/conferences/previous/ottawa/en/index.html

Young, J. (2004). "Becoming different": accessing university from a low socioeconomic community—barriers and motivators. Systemic Practice and Action Research, 17(5), 425-469.

Zoghi, M., Brown, T., Williams, B., Roller, L., Jaberzadeh, S., \& Palermo, C. (2010). Learning style preferences of Australian health science students". Allied Health, 39, 95-103. 